\title{
Preterm Birth and Necrotizing Enterocolitis Alter Gut Colonization in Pigs
}

\author{
MALENE S. CILIEBORG, METTE BOYE, LARS MØLBAK, THOMAS THYMANN, AND PER T. SANGILD
}

\begin{abstract}
Department of Human Nutrition [M.S.C., T.T., P.T.S.], University of Copenhagen, DK-1870 Frederiksberg, Denmark; National Veterinary
\end{abstract} Institute [M.S.C., M.B., L.M.], Technical University of Denmark, DK-1790 Copenhagen, Denmark

\begin{abstract}
Necrotizing enterocolitis (NEC) in preterm neonates is dependent on bacterial colonization, but it remains unclear whether a particular microbiota or specific pathogens are involved. We hypothesized that gut colonization differs between preterm and term neonates and that overgrowth of Clostridium perfringens predisposes to NEC. By using terminal-RFLP and FISH, we characterized the gut microbiota of preterm, caesarean-delivered, formula-fed pigs $(n=44)$ with or without NEC and of formula- or colostrum-fed term, and vaginally born pigs $(n=13)$. A different microbiota with high $C$. perfringens abundance was observed in preterm pigs with NEC compared with healthy individuals. However, immunization against $C$. perfringens toxins did not prevent NEC, and $C$. perfringens inoculation $\left(3.6 \times 10^{8} \mathrm{cfu} / \mathrm{d}\right)$ failed to induce NEC $(n=16)$, whereas prophylactic broad-spectrum antibiotics treatment prevented NEC $(n=24)$. Colonization in both groups of term pigs differed from preterm pigs and was dominated by Lactobacilli spp. In conclusion, gestational age (GA) and NEC influence neonatal gut colonization, whereas diet has minor effects. C. perfringens is more abundant in pigs with NEC but rather as a consequence than a cause of disease. The general bacterial load and underdeveloped gut immune responses in preterm neonates seem more important for NEC development than specific pathogens. (Pediatr Res 69: 10-16, 2011)
\end{abstract}

$\mathrm{B}$ acterial colonization of the immature intestine is a contributing factor to the development of necrotizing enterocolitis (NEC), a severe intestinal disease in preterm infants. Preterm neonates are generally less exposed to maternal contact and breast milk, which is considered to initiate a balanced gut colonization that provides immunological tolerance and reduced intestinal inflammation (1). Observational studies show that compared with full-term birth and mother's milk feeding, preterm birth and formula feeding predispose to a different fecal microbiota and to NEC $(2,3)$. Hospital environments and delivery method affect the microbiota but have not consistently been linked with NEC in infants $(4,5)$ or pigs (6). Reduced digestive functions and motility of the immature intestine result in accumulated undigested food, which predisposes to bacterial overgrowth and excessive fermentation. Infant NEC is often associated with abundant Escherichia coli, Klebsiella, Streptococcus, and Clostridium spp. (7,8). Although no single pathogen has been identified (9-11),

Received June 2, 2010; accepted August 26, 2010.

Correspondence: Per T. Sangild, Ph.D., Department of Human Nutrition, Faculty of Life Science, University of Copenhagen, 30 Rolighedsvej, DK-1958 Frederiksberg C, Denmark; e-mail: psa@life.ku.dk

Supported by the Danish Strategic Research Council under the program Health, Food, and Welfare.
Clostridium perfringens has been associated with NEC in infants and pigs (12-14).

A general risk of infection and the association between bacterial overgrowth and NEC have led to widespread use of antibiotics for preterm infants. However, prolonged antibiotic administration results in a microbiota dominated by fewer species that potentially predispose to $\operatorname{NEC}(11,12)$. It remains unknown whether short-term broad-spectrum antibiotic treatment, i.v. and/or orally, will prevent NEC (15).

To elucidate how gut colonization is affected by gestational age (GA), diet, and delivery mode and the relationship with NEC risk, we characterized the luminal- and tissue-associated gut microbiota in preterm and term pigs using culturedependent methods and molecular methods targeting the bacterial 16S rRNA gene: terminal RFLP (T-RFLP) and FISH. We hypothesized that gut colonization differs between caesarean-delivered preterm pigs and pigs born vaginally at term. We predicted that $C$. perfringens is a dominating species in preterm pigs with NEC and that immunization against $C$. perfringens toxins or inoculation with $C$. perfringens alters NEC incidence. Finally, we hypothesized that prophylactic broad-spectrum antibiotics inhibit gut colonization and prevent NEC in preterm pigs.

\section{MATERIALS AND METHODS}

Study 1: gut colonization in preterm and term pigs. Thirteen term pigs from one sow (Large White $\times$ Danish Landrace $\times$ Duroc) were vaginally born at term (114 -d gestation). The pigs either remained with the sow to suckle colostrum (MAT-C, $n=7$ ) or were transferred to temperature- and oxygen-controlled incubators (Air-Shields, Hatboro, PN), fitted with orogastric catheters as previously described (14) and fed formula (MAT-F, $n=6$ ). All term pigs were killed for sample collection $38-43 \mathrm{~h}$ after birth. According to our standard protocol (14), 44 preterm pigs from three sows were delivered by caesarean section at 91-93\% gestation, transferred to incubators, and fitted with vascular catheters (4 Fr) into the umbilical aorta and with 6-Fr orogastric catheters and fed with infant formula $(15 \mathrm{~mL} / \mathrm{kg} / 3 \mathrm{~h})$. Preterm pigs were stratified after weight into three treatment groups as follows: 1) untreated controls $(n=22) ; 2)$ TOXICOL pigs $(n=4)$ that within $12 \mathrm{~h}$ of age were given serum $[15 \mathrm{~mL} / \mathrm{kg}$ intraarterial (i.a.)] from a pregnant sow immunized with toxins from $C$. perfringens type $\mathrm{C}$ and $E$. coli antigens (Schering-Plough, Farum, Denmark); and 3) COLERADO pigs $(n=18)$ given antiserum with anti-toxins for $C$. perfringens type $\mathrm{C}$ and $\mathrm{D}(2.5 \mathrm{~mL} / \mathrm{kg}$ i.a. $)$ and $2.5 \mathrm{~mL}$ p.o., CO Serum Company, Denver, CO). The pigs were continuously evaluated for clinical NEC symptoms such as lethargy, abdominal distention, and bloody diarrhea. Two days after birth, pigs were killed (pentobarbiturate, i.a.) for sample collection unless significant NEC symptoms developed beforehand.

\footnotetext{
Abbreviations: i.a., intraarterial; NEC, necrotizing enterocolitis; TPN, total parenteral nutrition; T-RFLP, terminal RFLP; T-RF, terminal restriction fragment
} 
All studies were approved by the National Committee on Animal Experimentation, Denmark.

Study 2: $C$. perfringens type A inoculation. Sixteen caesarean-delivered preterm pigs from two sows were fitted with umbilical and orogastric catheters as described above. Total parenteral nutrition (TPN) was administered for $2 \mathrm{~d}$ as previously described (16) before full formula feeding $\left(15 \mathrm{~mL} / \mathrm{kg}^{-} / 3 \mathrm{~h}\right)$ for 36-48 h until killing and sample collection. The pigs were randomized after weight into controls $(n=10)$ and pigs inoculated with $3.6 \times 10^{8} \mathrm{C}$. perfringens type $\mathrm{A}((n=6)$. After study 1 , multiplex PCR targeting the genes for $\alpha, \beta, \beta 2, \epsilon$, and $\iota$ toxins (17) identified $C$. perfringens type A as the only $C$. perfringens type isolated from preterm pigs across several previous studies (data not shown). C. perfringens type A isolated from a previous NEC pig was grown anaerobically overnight in brain heart infusion (BHI) broth (National Veterinary Institute, Copenhagen, Denmark). At 4, 10, 22, and $26 \mathrm{~h}$ postpartum, $1 \mathrm{~mL} \mathrm{C}$. perfringens type A culture was given with $1 \mathrm{~mL}$ formula to preterm pigs via the oral catheter to a total daily dose of $3.6 \times 10^{8} \mathrm{cfu}$. Bacterial density $(\mathrm{cfu} / \mathrm{mL})$ was determined by anaerobic plating on $C$. perfringens selective tryptose sulfite cycloserine (TSC) plates (National Veterinary Institute, Copenhagen, Denmark).

Study 3: prophylactic antibiotics. Caesarean-delivered preterm pigs from two sows given first TPN then formula, as described above, were allocated into controls $(n=13)$ and a treatment group receiving oral and systemic broad-spectrum antibiotics, frequently used in NICU (ampicillin, gentamicin, metronidazole, ANTI, $n=11$ ). Ampicillin (totally $200 \mathrm{mg} / \mathrm{kg} / \mathrm{d}$ ) was given twice daily by oral $(0.5 \mathrm{~mL} / \mathrm{kg}: 500 \mathrm{mg}$ tablets dissolved in $5 \mathrm{~mL}$ saline; NordMedica, Copenhagen, Denmark) and i.m. administration $(0.175 \mathrm{~mL} / \mathrm{kg}$ : $1 \mathrm{~g}$ dissolved in $3.5 \mathrm{~mL}$ saline; Pentrexyl, Bristol-Myers Sqibb, Bromma, Sweden). Gentamicin (totally $2.5 \mathrm{mg} / \mathrm{kg} / \mathrm{d}$ ) was given once daily orally and i.m., with $2.5 \mathrm{mg} / \mathrm{kg} / \mathrm{d}$ per administration route $(0.1 \mathrm{~mL} / \mathrm{kg}$ : $50 \mathrm{mg} / \mathrm{mL}$ diluted in saline to $25 \mathrm{mg} / \mathrm{mL}$; KU-LIFE Pharmacy, Copenhagen, Denmark). Metronidazole (totally $40 \mathrm{mg} / \mathrm{kg} / \mathrm{d}$ ) was administered by two oral doses $(0.25$ mL/kg: 40 mg/mL; Flagyl; Sanofi Aventis, Hørsholm, Denmark) and two i.m. injections $(10 \mathrm{mg} / \mathrm{kg} / \mathrm{d} ; 5 \mathrm{mg} / \mathrm{mL}$; Actavis, Hafnarfjordur, Island). Systemic and oral antibiotics were given simultaneously together with formula (3 $\mathrm{mL} / \mathrm{kg}$ ). Control pigs were injected with saline.

Tissue collection and pathological evaluations. For all three studies, five regions of the gastrointestinal organs (stomach, proximal, middle, and distal small intestine, and colon) were evaluated for NEC lesions according to our macropathological scoring system: $1=$ absence of lesions, $2=$ local hyperemia, inflammation, and edema, 3 = hyperemia, extensive edema, and local hemorrhage, 4 = extensive hemorrhage, $5=$ local necrosis and pneumatosis intestinalis, and $6=$ extensive necrosis and pneumatosis intestinalis. NEC was defined as a score of minimum 3 in minimum one region (16).

For study 1, sections of distal small intestine were formalin fixated and paraffin embedded for mucosal morphometry analyses, FISH, and HE staining (16). Histomorphological measurements of 10 full length villi and 10 crypts for each pig were performed by the software of SoftWoRx Explorer Version 1.1 (Applied Precision, Issaquah, WA) on scanning images of 3- $\mu \mathrm{m}$ cross sections (ArrayWoRx ${ }^{\mathrm{e}}$ microarray scanner, Applied Precision).

Microbiology. Luminal contents from distal small intestine (study 1) or cecum (studies 2 and 3 ) were sampled and stored at $4^{\circ} \mathrm{C}$ until microbiological characterization. Small intestinal contents were cultured anaerobically on calf blood agar plates (SSI Diagnostika, Hillerød, Denmark) and TSC medium for enumeration of total anaerobes and $C$. perfringens, respectively. Cecum contents were enumerated after anaerobic and aerobic cultivation on calf blood agar. Colonies with different morphology (studies 1 and 3) were selected for $16 \mathrm{~S}$ rDNA sequencing (Agowa, Berlin, Germany) using universal PCR primers and sequence primers S-D-Bact-0008-a-S-20 and S-*-Univ0519-a-A-18 (18) (DNA Technology, Aarhus, Denmark) as previously de- scribed (18). The chromatograms were assembled in BioNumerics Version 4.5 (Applied Maths, Kortrijk, Belgium) and blasted for identification (http://www.ncbi.nlm.nih.gov).

The microbiota of small intestinal contents (study 1) and of distal small intestinal tissue (study 3) was characterized by T-RFLP as previously described (18). Extracted DNA (QIAamp DNA Stool Mini Kit; Qiagen, Hilden, Germany) were adjusted to $5 \mu \mathrm{g} / \mathrm{mL}$ (NanoDrop Technologies, Wilmington, DE), PCR amplified, and digested with restriction enzyme $C f o \mathrm{I}$ (New England Biolabs, Ipswich, MA) before denaturation and loading on denaturing polyacrylamide gels for sequencing (ABI PRISM 377 DNA; PE Biosystems) as previously described (18). The resulting terminal restriction fragments (T-RFs) were aligned against internal standards (PE GeneScan 500 ROX Size Standard; Applied Biosystems, Warrington, United Kingdom, and PE GENEFLO 625 DNA Ladder ROX Size Standard; CHIMERx, Milwaukee, WI) in BioNumerics Version 4.5 (Applied Maths). For standardization, T-RF intensity relative to total sample intensity was calculated, and identity of dominating T-RFs was suggested by in silico digest in the MiCA software (http://mica.ibest.uidaho.edu/digest.php) using the RDPII database. Only T-RFs with a mean intensity $>0.01$ were presented graphically. Another T-RFLP using restriction enzymes $M s p \mathrm{I}$ and $R s a \mathrm{I}$ (20 U; New England Biolabs) was performed on selected samples. Dominating T-RFs from the two T-RFLP analyses were compared with validate and increase resolution of the identified $C f o$ I-T-RFs.

FISH with a general 16S rRNA bacterial DNA-probe labeled with red isothiocyanate derivative $(\mathrm{Cy} 3$, Table 1$)$ was performed on cross sections of distal small intestine from pigs in study 1 as described previously (14). Tissue slides were scanned (ArrayWoRx ${ }^{\mathrm{e}}$ microarray scanner; Applied Precision) and given a FISH score based on abundance and position of bacterial microcolonies: $1=$ no or very few microcolonies, $2=$ few microcolonies, $3=$ abundant colonies in the intestinal lumen, and $4=$ abundant colonies closely adhering to the mucosa. Tissue sections with visible microcolonies $(n=30)$ were further hybridized with a $C$. perfringens-specific Cy3-labeled probe (Table 1) and given $C$. perfringens-FISH scores as above. Selected species or genera identified by cultivation or T-RFLP were further investigated by FISH with specific probes either previously published $(14,18,19)$ (Table 1) or designed using the software ARB (http://www.arb-home.de) and the database Greengenes (http://greengenes.lbl.gov/cgi-bin/nph-index.cgi) (Table 1). Affinity and specificity were tested by hybridization of porcine lung tissue infected with pure culture and by BLAST on the NCBI homepage, respectively.

Calculations and statistical analyses. All results are presented as means and SEM. Group differences in NEC incidences were tested using Fisher exact test (SAS/STAT Version 9.1; SAS Institute, Cary, NC). Group differences in bacterial enumeration were tested using $t$ test, and the mean relative T-RF intensities were tested using Wilcoxon Monte Carlo Estimates Exact Test in SAS. Based on overall similarity of all T-RFs, similarity (Dice) coefficient and principal component analysis (PCA) was generated in BioNumerics Version 4.5 (Applied Maths). All remaining parameters were tested with a two-way ANOVA using the SAS PROC MIXED procedure with treatment, diet, and sex as fixed variables and pigs and sows as random variables. For all analyses, $p<0.05$ was the critical level of significance.

\section{RESULTS}

\section{Clinical Outcomes}

Study 1. Some of the preterm pigs developed NEC symptoms $23 \mathrm{~h}$ after introduction of enteral feeding $(12 / 44,27 \%)$,

Table 1. Oligonucleotide probes* used for visualization of bacteria by FISH

\begin{tabular}{llll}
\hline \multicolumn{1}{c}{ Probe (dye) } & \multicolumn{1}{c}{ Target bacteria } & \multicolumn{1}{c}{ Sequence } & \multicolumn{1}{c}{$\begin{array}{c}\text { Reference or strain used } \\
\text { for affinity test }\end{array}$} \\
\hline S-D-bact-0338 (CY3 and FITC) & General bacteria & $5^{\prime}$-GCTGCCTCCCGTAGGAGT-3' & Ref. 18 \\
S-S-Cperfring-185 (FITC) & Clostridium perfringens & $5^{\prime}$-TGGTTGAATGATGATGCC-3' & Ref. 14 \\
L-S-Kpneu-1705 (Cy3) & Klebsiella pneumoniae & $5^{\prime}$-TACACACCAGCGTGCCTT-3' & Isolate verified by sequencing \\
L-S-Efaecium-347 (Cy3) & Enterococcus faecium & $5^{\prime}$-GTGTCTTCCACATTTCGT-3' & Type strain ATCC 19434 \\
S-S-Acal-446 (Cy3) & Acinetobacter calcoaceticus & $5^{\prime}$-AATACTAGTAGCCTCCTC-3' & Isolate verified by sequencing \\
S-Salac-0078 (Cy3) & Streptococcus alactolyticus & $5^{\prime}$-CAAAAGAAGCAAGCTCC-3' & Type strain ATCC 43077 \\
LGC354A-lactob (FITC) & Lactobacillus spp. & $5^{\prime}$-TGGAAGATTCCCTACTGC-3' & Ref. 19 \\
\hline
\end{tabular}

Name, dye, target, sequence, and strain used for affinity test are shown.

* All probes obtained from MWG-BIOTECH. 

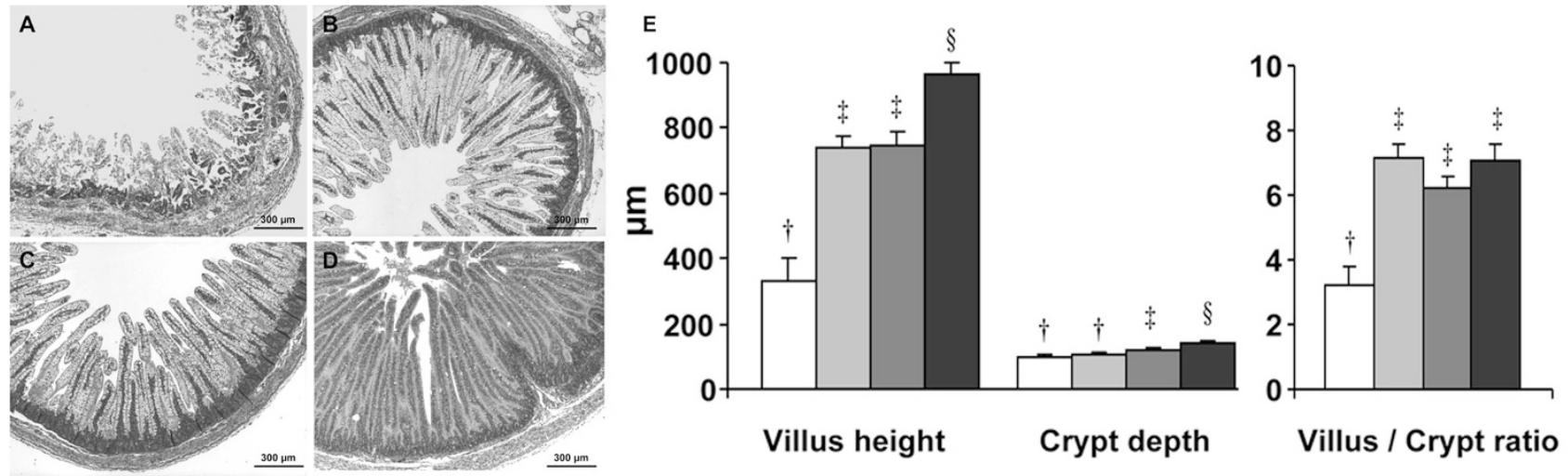

Figure 1. Cross sections of distal small intestine (HE stain, $25 \times$ magnification) from a preterm NEC pig $(A)$, a healthy preterm pig $(B)$, formula-fed term pig $(C)$, and a colostrum-fed term pig $(D)$. Histomorphometry of distal small intestine of preterm pigs with NEC $\square$, preterm healthy pigs $\square$, term formula pigs $\square$, and term colostrum pigs $\square(E)$. Means \pm SEM. Different superscript symbols indicate significant difference.

and NEC pathology was confirmed at necropsy. In pigs with NEC, histopathology of the distal small intestine revealed atrophic mucosa with stunted to disintegrated villi, altered mucosal proportions, hemorrhage, and separation of submucosa, muscularis, and serosa (Fig. 1). Pigs with NEC had a significantly higher mean NEC score across all gastrointestinal regions than healthy preterm pigs $(3.8 \pm 0.4$ versus $1.1 \pm 0.0, p<0.05)$. Immunization against $C$. perfringens toxins did not prevent NEC because incidences for TOXICOL, COLERADO, and control pigs $(27 \%, 6 / 22$ for immunized and control pigs), and NEC scores were not different $(p>0.5)$.

Study 2. C. perfringens type A inoculation did not induce a higher incidence of NEC among $C$. perfringens type A pigs $(1 / 6)$ versus control pigs (1/10). Subclinical intestinal lesions not specific for NEC were observed in two $C$. perfringens type A pigs and in one control pig (

Study 3. No ANTI pigs (0/11) and 11 control pigs (85\%) were diagnosed with NEC. However, minor intestinal lesions $($ score $=2$ ) were observed in several ANTI pigs $(9 / 11)$ in $1-4$ gut regions.

\section{Microbiology}

Study 1. There was no microbiological response to immunization (data not shown). Because clinical effects were also absent, TOXICOL and COLERADO pigs were pooled with the control pigs for further analyses. Instead, comparisons were made between preterm pigs that were healthy $(n=32)$ or had NEC $(n=12)$. These groups were further compared with the two groups of term pigs, which irrespective of diet did not develop NEC.

Numbers of total anaerobic bacteria did not differ between NEC and healthy preterm pigs $\left(4.1 \times 10^{9} \pm 2.0 \times 10^{9}\right.$ versus $\left.2.4 \times 10^{9} \pm 1.4 \times 10^{9} \mathrm{cfu} / \mathrm{g}, p=0.5\right)$, but NEC pigs tended to have more $C$. perfringens than healthy preterm pigs $(2.3 \times$ $10^{9} \pm 1.8 \times 10^{9}$ versus $1.3 \times 10^{8} \pm 6.5 \times 10^{7} \mathrm{cfu} / \mathrm{g}, p=$ 0.1 ). FISH and subsequent scanning of small intestinal tissue (Fig. $2 A$ and $B$ ) visualized bacterial abundance in situ and revealed that pigs with NEC had higher FISH scores of both general bacteria and $C$. perfringens compared with healthy preterm pigs (Table 2). Based on 97-100\% similarity in $16 \mathrm{~S}$ rDNA sequence, 13 species were identified from small intestinal content (GenBank accession numbers in brackets): Acinetobacter calcoaceticus (GQ483513), Bacillus cereus (GQ483514), C. perfringens (GQ483515), Enterobacter sp. [E. coli or Shigella sp. (GQ483516)], Enterobacter homaechei (GQ483517), Enterococcus faecium (GQ483518), Klebsiella pneumoniae (GQ483519), Lactobacillus sakei (GQ483520), Leuconostoc mesenteroides (GQ483521), Staphylococcus aureus (GQ483522), Staphylococcus chromogenes (GQ483523), Streptococcus alactolyticus (GQ483524), and Streptococcus
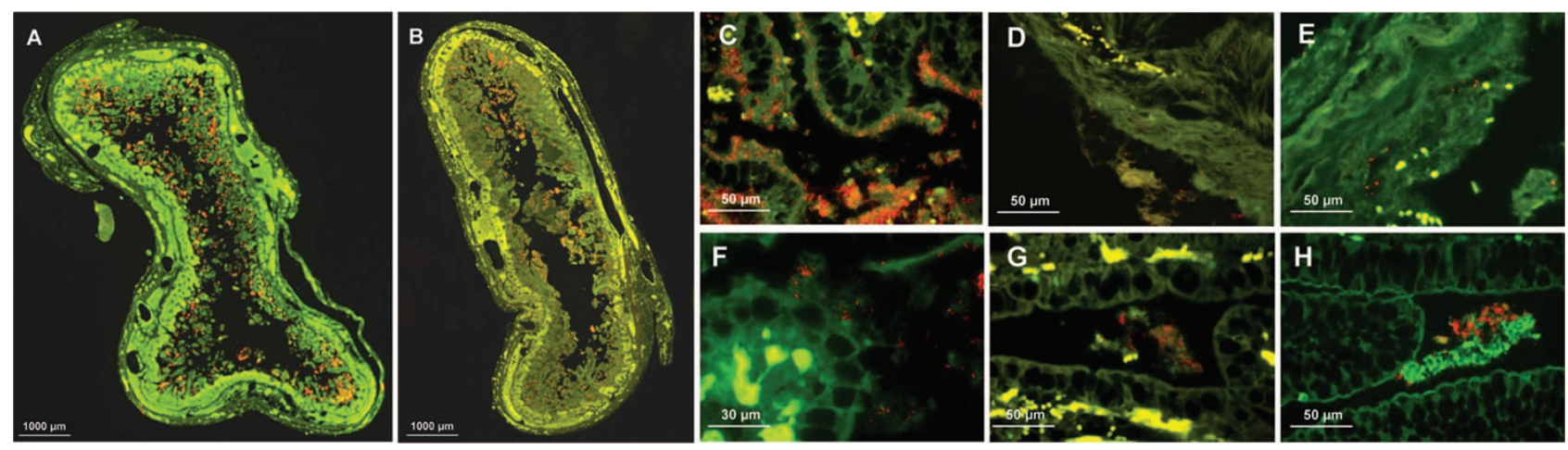

Figure 2. FISH of distal small intestinal cross sections. Scanning images visualize abundances of general bacteria $(A)$ and $C$. perfringens $(B)$ in preterm NEC pigs. Microscopy images (all $400 \times$ magnification) demonstrate close mucosal association $(C)$ and epithelial translocation $(D)$ of $C$. perfringens and presence of E. faecium $(E)$, K. pneumoniae $(F)$, and S. alactolyticus $(G)$ in preterm pigs and Lactobacillus spp. in term pigs $(H)$. Probes were labeled with red Cy3 except for Lactobacillus spp. labeled with green FITC. 
Table 2. Characteristics of preterm and term pigs from study 1

\begin{tabular}{|c|c|c|c|c|}
\hline & \multicolumn{2}{|c|}{ Preterm pigs } & \multicolumn{2}{|c|}{ Term pigs } \\
\hline & NEC & Healthy & Formula & Colostrum \\
\hline Birth weight (g) & $1175 \pm 56 \dagger$ & $1022 \pm 40 \div$ & $1331 \pm 131 \dagger$ & $1382 \pm 133 \dagger$ \\
\hline Weight gain (g) & $-217 \pm 97 \dagger$ & $-70 \pm 7 \dagger$ & $52 \pm 16 \ddagger$ & $228 \pm 35 \S$ \\
\hline FISH score: general bacteria & $3.2 \pm 0.3 \dagger$ & $1.8 \pm 0.1 \ddagger$ & $2.5 \pm 0.0 \dagger \ddagger$ & $2.0 \pm 0.2 末$ \\
\hline FISH score: $C$. perfringens & $2.6 \pm 0.4 \dagger$ & $1.5 \pm 0.2 \ddagger$ & $1.3 \pm 0.3 \dagger+$ & $1.2 \pm 0.2 \ddagger$ \\
\hline Villous height $(\mu \mathrm{m})$ & $330 \pm 70 \dagger$ & $738 \pm 37 \doteqdot$ & $745 \pm 47 \ddagger$ & $964 \pm 35 \S$ \\
\hline Crypt depth $(\mu \mathrm{m})$ & $101 \pm 8 \dagger$ & $107 \pm 2 \dagger$ & $122 \pm 3 \ddagger$ & $141 \pm 7 \S$ \\
\hline Villous/crypt ratio & $3.2 \pm 0.6 \dagger$ & $7.1 \pm 0.4 \div$ & $6.2 \pm 0.4 \neq$ & $7.1 \pm 0.5 \ddagger$ \\
\hline
\end{tabular}

See text for explanation of FISH scores. Values are represented as mean \pm SEM.

Means not sharing same superscript symbol are significantly different $(p<0.05)$.

Table 3. Average number of T-RFs (an index of diversity) and the similarity index (Dice coefficient) after $\mathrm{CfoI}$ digest in study 1

\begin{tabular}{|c|c|c|c|c|c|c|}
\hline & \multicolumn{3}{|c|}{ Preterm pigs } & \multicolumn{3}{|c|}{ Term pigs } \\
\hline & All preterm & $\begin{array}{c}\text { NEC } \\
(n=12)\end{array}$ & $\begin{array}{l}\text { Healthy } \\
(n=32)\end{array}$ & All term & $\begin{array}{l}\text { Colostrum } \\
(n=7)\end{array}$ & $\begin{array}{c}\text { Formula } \\
(n=6)\end{array}$ \\
\hline T-RFs & $16.5^{*}$ & $12.7 \dagger$ & $17.9^{*}$ & $23.6 \ddagger$ & $25.9 \ddagger$ & $20.9^{*} \div$ \\
\hline Dice coefficient & $47.9 \pm 0.5 \dagger$ & $56.3 \pm 1.8^{*} \ddagger$ & $47.9 \pm 0.7 \dagger$ & $54.0 \pm 1.3^{*}$ & $62.3 \pm 2.2 \ddagger$ & $59.6 \pm 2.8 *$ \\
\hline
\end{tabular}

Values are represented as mean \pm SEM. Averages not sharing the same superscript symbols are significantly different. The Dice coefficient indicates the overall microbiota similarity using the average number of T-RF's common for two pigs within the same group. A high coefficient indicates a high degree of similarity.

dysgalactiae (GQ483525). FISH on small intestinal tissue with specific probes confirmed the presence of several of $C$. perfringens, E. faecium, K. pneumonia, S. alactolyticus, and Lactobacillus spp. (Fig. $2 C-H$ ).

T-RFLP with restriction enzyme $C f o \mathrm{I}$ revealed totally 105 different T-RFs ranging from $62-632 \mathrm{bp}$. Preterm pigs had in average $16.5 \pm 0.9$ different T-RFs, and totally, 80 different T-RFs represented the group. In average, less numbers of T-RFs were observed in the preterm NEC versus preterm healthy pigs and term pigs (Table 3), indicating low bacterial diversity in this group. A mean of $23.6 \pm 2.0$ per pig and totally 72 different T-RFs were observed in the term group. Diversity was generally higher in vaginally born term pigs compared with cesarean-delivered preterm pigs, although formula-fed term pigs and healthy preterm pigs were not significantly different (Table 3). Different colonization patterns between NEC and healthy preterm pigs, between preterm and term pigs, and to a lesser extent between formula- and colostrum-fed term pigs were revealed as spatial separation in the PCA plot (Fig. 3). High interindividual variation was noted among the healthy preterm pigs and coincided with a significantly lower mean similarity coefficient for healthy preterm pigs compared with the other groups (Table 3). Dice coefficients between different groups of pigs were relatively low (data not shown) indicating low microbiota similarity between different groups of pigs. Graphical presentations of dominating T-RFs reveal the most important differences between groups of pigs (Fig. 4), with C. perfringens dominant in preterm pigs with NEC and Lactobacillus spp. dominant in both groups of term pigs.

T-RFLP with $M s p$ I and $R s a \mathrm{I}$ resulted in 145 different T-RFs ranging from 60 to $604 \mathrm{bp}$ (data not shown). Comparing T-RFs intensities and distributions from both T-RFLP analyses proposed identity of the dominating $C f o \mathrm{I}-\mathrm{T}-\mathrm{RF}$ (Table 4 ). In short, T-RFs probably representing C. perfringens, E. faecium, $K$. pneumoniae, and A. calcoaceticus were dominant in preterm pigs. Increased $C$. perfringens density in NEC pigs represented the main difference between healthy pigs and NEC pigs. T-RFs probably representing Lactobacillus spp. dominated in all term pigs and to some extent in healthy preterm pigs (Fig. 4).

Study 2. C. perfringens type A-inoculated pigs had higher numbers of $C$. perfringens than control pigs $\left(1.1 \times 10^{9} \pm\right.$

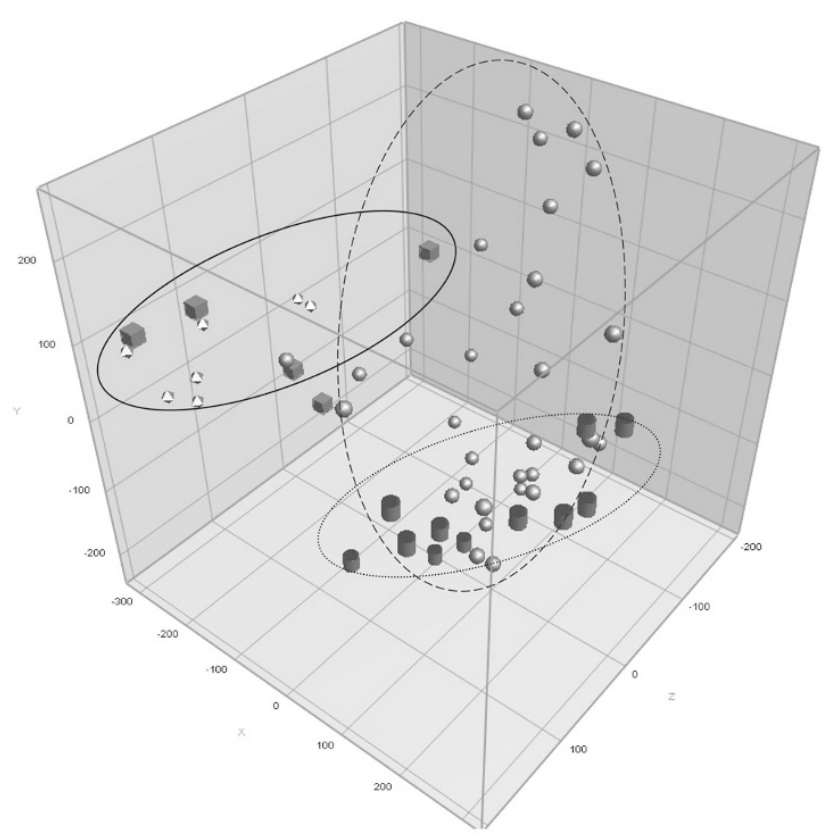

Figure 3. PCA analysis of T-RFLP results shows a three-dimensional separation of pigs according to overall similarity of the small intestinal microbiota. Clustering (indicated by different ellipses) indicates high similarity whereas separation indicates low similarity. Marbles (indicated by broken line), preterm healthy pigs; barrels (indicated by dotted line), preterm NEC pigs; boxes, term formula-fed pigs; and diamonds, term colostrum-fed pigs (both groups of term pigs indicated by solid line). 


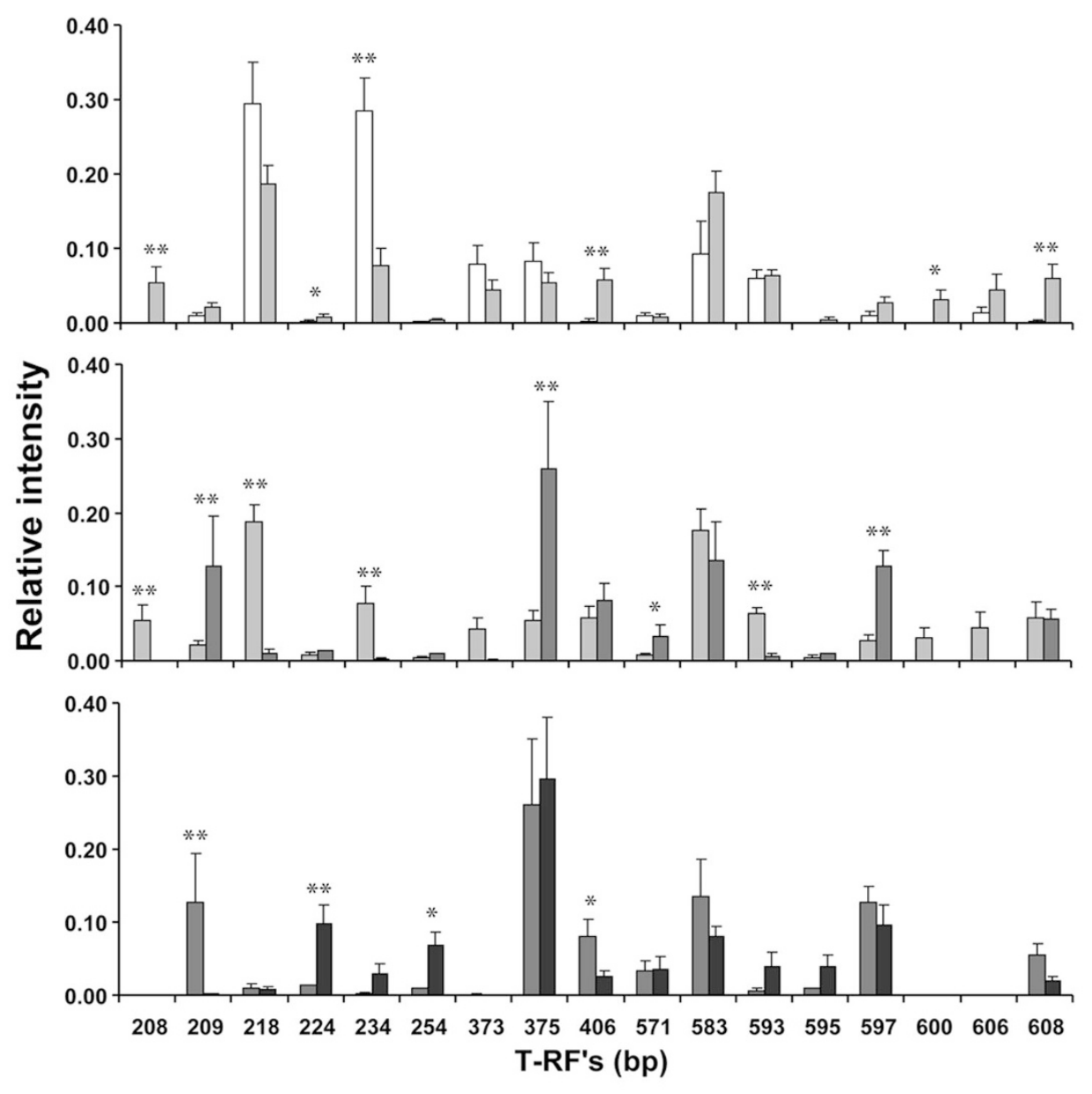

Figure 4. Relative intensity of dominating T-RFs in preterm pigs with NEC $\square$, preterm healthy pigs $\square$, term formula-fed pigs $\square$, and term colostrum-fed pigs $\square$. Means \pm SEM. Stars indicate group differences $(* p<0.05$ and $* * p<0.01)$

Table 4. Proposed identification of dominating T-RFs (study 1) was based on comparing between the two analyses (CfoI and MspI + RsaI) T-RFs intensities and overlapping distribution among pigs

\begin{tabular}{|c|c|c|c|c|}
\hline \multicolumn{2}{|c|}{ Observed T-RFs } & \multirow[b]{2}{*}{ Possible identification } & \multirow[b]{2}{*}{ Predominant in } & \multirow[b]{2}{*}{ Confirmed with FISH } \\
\hline$C f o \mathrm{I}$ & $M s p \mathrm{I}+R s a \mathrm{I}$ & & & \\
\hline 208 & 490 & Acinetobacter calcoaceticus & Preterm pigs, healthy & No \\
\hline 209 & 154 & Turicibacter spp. & Term pigs, formula fed & Not performed \\
\hline 218 & 73 & Enterococcus faecium & Preterm pigs, all & Yes, but at lower abundance \\
\hline 224 & 180 & Lactobacillus delbrueckii & Term pigs, colostrum fed & Yes, at genus level \\
\hline 234 & 453 & Clostridium perfringens & Preterm pigs, NEC & Yes \\
\hline 254 & 180 & Lactobacillus delbrueckii & Term pigs, colostrum-fed & Yes, at genus level \\
\hline 373 & 496 & Klebsiella pneumoniae & Preterm pigs, all & Yes \\
\hline 375 & 429 & Escherichia coli & Term pigs, all & Not performed \\
\hline 406 & 572 & Lactobacillus fermentum/rennanqilfy & Preterm (healthy) and term pigs & Yes, at genus level \\
\hline 583 & $496 / 560$ & Streptococcus alactolyticus & Preterm and term pigs & Yes \\
\hline 597 & 572 & Lactobacillus acidophilus/brevis/rennanqilfy/plantarum & Term pigs, all & Yes, at genus level \\
\hline 600 & 572 & Lactobacillus spp. & Preterm (healthy) & Yes, at genus level \\
\hline 606 & 572 & Lactobacillus spp. & Preterm (healthy) & Yes, at genus level \\
\hline 608 & 572 & Lactobacillus spp./Weissella spp. & Preterm (healthy) & Yes, at genus level \\
\hline
\end{tabular}

All except Lactobacilli spp. and Turicibacter spp. were isolated from intestinal content.

$3.2 \times 10^{8}$ versus $\left.1.4 \times 10^{8} \pm 8.8 \times 10^{7} \mathrm{cfu} / \mathrm{mL}, p<0.01\right)$. Numbers of total anaerobic bacteria did not differ.

Study 3. Compared with controls, ANTI pigs had less total bacteria (aerobes: $2.6 \times 10^{5} \pm 1.1 \times 10^{5}$ versus $7.5 \times 10^{9} \pm$ $1.4 \times 10^{9}, \mathrm{cfu} / \mathrm{mL}$ and anaerobes: $2.6 \times 10^{5} \pm 1.1 \times 10^{5}$ versus $7.6 \times 10^{9} \pm 1.4 \times 10^{9} \mathrm{cfu} / \mathrm{mL}$, both $\left.p<0.0001\right)$. Six Gram-positive species were isolated from ANTI pigs: $B$. cereus (GQ483526), Clostridium paraputrificum (GQ483527), C. perfringens (GQ483528), Cronobacter sakazakii (GQ483529), E. faecium/hirae (GQ483530/GQ483531), and Staphylococcus pasteuri (GQ483532). PCR product was obtained from only four of 11 ANTI pigs, and to avoid misleading conclusions, no detailed analysis of the T-RFLP results was done from this study. 


\section{DISCUSSION}

The gut microbiota is important for NEC development in preterm neonates, but it remains unclear whether specific pathogens play a direct role and whether manipulation of the microbiota can alter NEC resistance. By using NEC-sensitive formula-fed preterm pigs, we demonstrate a different intestinal microbiota between formula-fed preterm and term pigs reared in the same environment. A more variable microbiota in healthy preterm pigs than in term pigs suggest that the immature gut facilitates distinct colonization patterns. Consistent with observations in infants (4,11), NEC development was associated with decreasing microbial diversity and overgrowth of $C$. perfringens. The $C$. perfringens overgrowth occurred as a response to disease, rather than as a cause of disease, because $C$. perfringens inoculation failed to induce NEC, and C. perfringens toxin immunization failed to protect against NEC. Bacterial load, more than the specific species composition, may be more important for NEC development, as indicated by the absence of NEC after broad-spectrum antibiotics use. Immature intestinal defense in preterm individuals leads to adverse host responses to a bacterial load that does not adversely affect term individuals.

Observations in infants $(9,13)$, preterm pigs $(14,16)$, and quails (20) propose a role for $C$. perfringens in NEC pathogenesis. Furthermore, a NEC-like disease in newborn production pigs (necrotizing enteritis) is prevented by providing colostrum or serum from sows immunized with $C$. perfringens type C and D toxins (21), and this stimulated our interest in the possible influence of $C$. perfringens types $C$ and D in NEC pathogenesis. T-RFLP and FISH revealed that overgrowth of $C$. perfringens in preterm NEC pigs accounted for the main colonization difference between healthy and diseased pigs. However, in contrast to previous results (14), toxicoltreatment of preterm pigs did not prevent NEC and effects were similarly absent after Colorado-serum treatment. Because later analysis revealed that only $C$. perfringens type A is present in our preterm pigs, this was chosen for inoculation in study 2 , but NEC incidence did not increase. These observations collectively reveal that $C$. perfringens is not a causative pathogen.

T-RFLP revealed a similar species pattern in the distal small intestine of healthy and NEC preterm pigs. The main colonization difference was related to altered abundances of general bacteria and specific species. FISH revealed overgrowth of general bacteria and $C$. perfringens in preterm pigs with NEC. Hence, an inappropriate microbiota does not alone induce NEC, but possibly high abundance of specific species and high bacterial load are required for NEC, together with intestinal insults such as ischemia and hypoxia. Several of the six bacterial species that escaped our prophylactic antibiotics treatment are commonly associated with human infections such as gaseous gangrene ( $C$. paraputrificum), neonatal meningitis (E. faecium), food poison (B. cereus), and infections and NEC in preterm infants (C. sakazakii) (22,23). Overgrowth of these species could potentially result in intestinal inflammation and necrosis as suggested from the observed lowgrade lesions. This is corroborated by the association in human infants among NEC antibiotic treatment and low fecal bacterial diversity $(11,12)$. Therefore, broad-spectrum antibiotics treatment may prevent NEC short-term but have negative colonization effects with increased risk of NEC in the long-term.

We compared preterm caesarean delivered, formula-fed pigs with term formula- or colostrum-fed pigs after spontaneous delivery. This is clinically relevant because of an increasing proportion of caesarean-delivered preterm infants $(4,24)$ but hampers firm conclusions regarding the effects of GA on colonization. However, a different colonization has been observed between vaginally- and caesarean-delivered neonates but has not been correlated with NEC or neonatal survival in preterm infants or pigs $(4,6,24)$. Thus, factors regarding host responses and feeding procedures in preterm neonates are probably more important for initial disease progression than the exact nature of the gut microbiota. Vaginally delivered term pigs that are reared with the sow are spontaneously colonized with maternal and environmental bacteria, presumably resulting in a natural and optimal microbiota $(1,4,25)$. In this study, this included higher abundance of Lactobacillus spp. and E. coli (T-RFs 224 and 254, 597 and 375), where the main differences between the term groups were within the Lactobacillus genera. Hence, this study shows that different diets and environments do not markedly affect intestinal colonization in term neonates and highlights the importance of the age-related host-responses rather than of diet or environment.

Compared with previous culture-independent studies on preterm infants and pigs that reported 10-36 different species $(4,11,13,26,27)$, T-RFLP revealed higher total bacterial diversity in the contents of distal small intestine of preterm pigs in this study. Previously, T-RFLP on distal intestinal tissue was performed to characterize the gut microbiota of preterm pigs and reflected only the mucosa-associated bacteria $(14,16)$. This study focused on luminal bacteria, which affect the host by modifying the luminal environment by metabolite production (e.g. short-chain fatty acids, organic acids, antimicrobial compounds, toxins, and immunomodulatory factors) $(5,6)$. Low fecal microbial diversity in preterm infants may result from highly hygienic procedures and common use of antibiotics in the NICUs.

Pigs and humans share similar developmental characteristics of the gastrointestinal tract, but at birth, gut structure, function, and immunity are less mature in pigs, than in infants (28), and $10 \%$ preterm delivery is associated with significant developmental immaturity. Shortly after formula feeding, $\sim 50 \%$ of preterm pigs spontaneously develops NEC and represents a valuable tool to study infant NEC in a highly controlled environment. Preterm pigs fed with colostrum show a NEC incidence of 5-10\% $(14,16)$, similar to that in preterm infants. However, the NEC-protective effects of colostrum are possibly not caused by microbiological effects because this study suggest that diet and environment had only marginal effect on the composition of the term gut microbiota. Also, in preterm pigs, the gut microbiota is not clearly related with diet although it is required for $\operatorname{NEC}(14,16)$. Therefore, on the basis of this study, we suggest that preterm delivery facilitates a distinct pattern of gut colonization that in combination with immature host immune responses lead to NEC in both pigs and infants. 
Acknowledgments. We thank Mette Schmidt, Richard Siggers, Mikkel Lykke Jensen, Michael Ladegaard Jensen, and Elin Skytte for assistance with the animal procedures. We also thank Annie Ravn Pedersen, Sophia Rasmussen, Joanna Amenuvor, Thomas Peter Boye Pihl, and Katja Kristensen at the National Veterinary Institute, DTU, for assistance with microbiological analyses. Finally, we thank Professor Randal Buddington at University of Memphis, USA, for critical comments to the manuscript.

\section{REFERENCES}

1. Calder PC, Krauss-Etschmann S, de Jong EC, Dupont C, Frick JS, Frokiaer H, Heinrich J, Garn H, Koletzko S, Lack G, Mattelio G, Renz H, Sangild PT, Schrezenmeir J, Stulnig TM, Thymann T, Wold AE, Koletzko B 2006 Early nutrition and immunity-progress and perspectives. Br J Nutr 96:774-790

2. Penders J, Thijs C, Vink C, Stelma FF, Snijders B, Kummeling I, van den Brandt PA, Stobberingh EE 2006 Factors influencing the composition of the intestinal microbiota in early infancy. Pediatrics 118:511-521

3. Schwiertz A, Gruhl B, Lobnitz M, Michel P, Radke M, Blaut M 2003 Development of the intestinal bacterial composition in hospitalized preterm infants in comparison with breast-fed, full-term infants. Pediatr Res 54:393-399

4. Hällström M, Eerola E, Vuento R, Janas M, Tammela O 2004 Effects of mode of delivery and necrotising enterocolitis on the intestinal microflora in preterm infants. Eur J Clin Microbiol Infect Dis 23:463-470

5. Malloy MH, Doshi S 2008 Cesarean section and the outcome of very preterm and very low-birthweight infants. Clin Perinatol 35:421-435 viii

6. Siggers RH, Thymann T, Jensen BB, Molbak L, Heegaard PM, Schmidt M, Buddington RK, Sangild PT 2008 Elective cesarean delivery affects gut maturation and delays microbial colonization but does not increase necrotizing enterocolitis in preterm pigs. Am J Physiol Regul Integr Comp Physiol 294:R929-R938

7. Hoy CM, Wood CM, Hawkey PM, Puntis JW 2000 Duodenal microflora in very-low-birth-weight neonates and relation to necrotizing enterocolitis. J Clin Microbiol 38:4539-4547

8. Lee JS, Polin RA 2003 Treatment and prevention of necrotizing enterocolitis. Semin Neonatol 8:449-459

9. Blakey JL, Lubitz L, Campbell NT, Gillam GL, Bishop RF, Barnes GL 1985 Enteric colonization in sporadic neonatal necrotizing enterocolitis. J Pediatr Gastroenterol Nutr 4:591-595

10. Duffy LC, Zielezny MA, Carrion V, Griffiths E, Dryja D, Hilty M, Cummings J, Morin F 2001 Bacterial toxins and enteral feeding of premature infants at risk for necrotizing enterocolitis. Adv Exp Med Biol 501:519-527

11. Wang Y, Hoenig JD, Malin KJ, Qamar S, Petrof EO, Sun J, Antonopoulos DA, Chang EB, Claud EC 2009 16S rRNA gene-based analysis of fecal microbiota from preterm infants with and without necrotizing enterocolitis. ISME J 3:944-954

12. Cotten CM, Taylor S, Stoll B, Goldberg RN, Hansen NI, Sanchez PJ, Ambalavanan N, Benjamin DK Jr 2009 Prolonged duration of initial empirical antibiotic treatment is associated with increased rates of necrotizing enterocolitis and death for extremely low birth weight infants. Pediatrics 123:58-66

13. de la Cochetiere MF, Piloquet H, des Robert C, Darmaun D, Galmiche JP, Roze JC 2004 Early intestinal bacterial colonization and necrotizing enterocolitis in premature infants: the putative role of Clostridium. Pediatr Res 56:366-370

14. Sangild PT, Siggers RH, Schmidt M, Elnif J, Bjornvad CR, Thymann T, Grondah ML, Hansen AK, Jensen SK, Boye M, Moelbak L, Buddington RK, Westrom BR, Holst JJ, Burrin DG 2006 Diet- and colonization-dependent intestinal dysfunction predisposes to necrotizing enterocolitis in preterm pigs. Gastroenterology 130:17761792

15. Bury RG, Tudehope D 2001 Enteral antibiotics for preventing necrotizing enterocolitis in low birthweight or preterm infants. Cochrane Database Syst Rev CD000405

16. Bjornvad CR, Thymann T, Deutz NE, Burrin DG, Jensen SK, Jensen BB, Molbak L, Boye M, Larsson LI, Schmidt M, Michaelsen KF, Sangild PT 2008 Enteral feeding induces diet-dependent mucosal dysfunction, bacterial proliferation, and necrotizing enterocolitis in preterm pigs on parenteral nutrition. Am J Physiol Gastrointest Liver Physiol 295:G1092-G1103

17. Baums CG, Schotte U, Amtsberg G, Goethe R 2004 Diagnostic multiplex PCR for toxin genotyping of Clostridium perfringens isolates. Vet Microbiol 100:11-16

18. Mølbak L, Thomsen LE, Jensen TK, Bach Knudsen KE, Boye M 2007 Increased amount of Bifidobacterium thermacidophilum and Megasphaera elsdenii in the colonic microbiota of pigs fed a swine dysentery preventive diet containing chicory roots and sweet lupine. J Appl Microbiol 103:1853-1867

19. Meier H, Amann R, Ludwig W, Schleifer KH 1999 Specific oligonucleotide probes for in situ detection of a major group of gram-positive bacteria with low DNA G + C content. Syst Appl Microbiol 22:186-196

20. Waligora-Dupriet AJ, Dugay A, Auzeil N, Huerre M, Butel MJ 2005 Evidence for clostridial implication in necrotizing enterocolitis through bacterial fermentation in a gnotobiotic quail model. Pediatr Res 58:629-635

21. Songer JG, Uzal FA 2005 Clostridial enteric infections in pigs. J Vet Diagn Invest $17: 528-536$

22. van Acker J, de Smet F, Muyldermans G, Bougatef A, Naessens A, Lauwers S 2001 Outbreak of necrotizing enterocolitis associated with Enterobacter sakazakii in powdered milk formula. J Clin Microbiol 39:293-297

23. Friedemann M 2009 Epidemiology of invasive neonatal Cronobacter (Enterobacter sakazakii) infections. Eur J Clin Microbiol Infect Dis 28:1297-1304

24. Haque KN, Hayes AM, Ahmed Z, Wilde R, Fong CY 2008 Caesarean or vaginal delivery for preterm very-low-birth weight $(<$ or $=1,250 \mathrm{~g})$ infant: experience from a district general hospital in UK. Arch Gynecol Obstet 277:207-212

25. Grönlund MM, Lehtonen OP, Eerola E, Kero P 1999 Fecal microflora in healthy infants born by different methods of delivery: permanent changes in intestinal flora after cesarean delivery. J Pediatr Gastroenterol Nutr 28:19-25

26. Millar MR, Linton CJ, Cade A, Glancy D, Hall M, Jalal H 1996 Application of 16S rRNA gene PCR to study bowel flora of preterm infants with and without necrotizing enterocolitis. J Clin Microbiol 34:2506-2510

27. Siggers RH, Siggers J, Boye M, Thymann T, Molbak L, Leser T, Jensen BB, Sangild PT 2008 Early administration of probiotics alters bacterial colonization and limits diet-induced gut dysfunction and severity of necrotizing enterocolitis in preterm pigs. J Nutr 138:1437-1444

28. Sangild PT 2006 Gut responses to enteral nutrition in preterm infants and animals. Exp Biol Med (Maywood) 231:1695-1711 